\title{
Tiktok, red simbiótica de la generación z para la realidad aumentada y el advergaming inmersivo
}

\author{
Tiktok, gen z symbiotic network for augmented reality and \\ immersive advergaming
}

\author{
Martín Ramallal, P. y Micaletto Belda, J. P.1 \\ Recibido: 19-04-2021 - Aceptado: 05-08-2021 \\ https://doi.org/10.26441/RC20.2-2021-A12
}

\begin{abstract}
RESUMEN: Los incesantes cambios en los modos de interrelación surgidos desde las TIC (Tecnologías de la Información y la Comunicación) traen vanguardistas maneras de comunicar, especialmente entre las nuevas generaciones. Las redes sociales (RRSS) parecen haberse convertido en el ágora de la postmodernidad y todo discurso que aspire a consolidarse debe adaptarse a las mismas. Las realidades mixtas (RMe), ejemplificadas en la realidad virtual $(R V)$ y la realidad aumentada (RA), no escapan a esta verdad axiomática. Las principales redes integran nativamente filtros RA a modo de capas de información enriquecida. Los anunciantes, ávidos de alcanzar a un público esquivo, se han percatado de su potencial narrativo.
\end{abstract}

Se expone como objetivo comprobar la compatibilidad de la RA como recurso para campañas de publicidad en RRSS apoyadas en advergames con estrategia transmedia. La metodología se sustenta en una triangulación cuyos vértices comprenden un estudio de caso, un análisis del discurso y un focus group (FG). Los resultados derivan del análisis de dos acciones emblemáticas insertas en TikTok, RRSS de crecimiento exponencial entre la generación $z$. Las campañas a examen son WeStart de Ma French Bank y You're On de Ray Ban. Se trae a discusión una serie de reflexiones respecto a las ventajas y peculiaridades de integrar estas estrategias como relato publicitario. Como conclusiones generales, la generación z parece estar llamada a adoptar la inmersión como algo propio de sus modos sociales y de su iconografía cibercultural, incluyendo esta premisa a la publicidad transmedia. Además, los advergames RA en RRSS encuentran en el transmedia un catalizador para alcanzar su máximo rendimiento.

Palabras clave: publicidad expandida; realidad aumentada; transmedia; publientretenimiento; juego publicitario.

ABSTRACT: The incessant changes in the modes of interrelation arising from ICT (Information and Communication Technologies) bring avant-garde ways of communicating, especially among the new generations. Social networks seem to have become the agora of postmodernity and any discourse that aspires to consolidate itself must adapt to them. Mixed realities (MRe), exemplified by virtual reality (VR) and augmented reality (AR) do not escape this axiomatic truth. The main networks natively integrate AR filters as layers of enriched information. Advertisers, eager to reach an elusive audience,

\footnotetext{
${ }^{1}$ Pablo Martín Ramallal es Doctor Interuniversitario en Comunicación (Universidades de Cádiz, Huelva, Málaga y Sevilla). Profesor responsable de las asignaturas Realidad Aumentada, Diseño Web, Diseño Gráfico y Tipografía en el Centro Universitario San Isidoro de la Universidad Pablo de Olavide. Líneas de investigación: Comunicación, Publicidad, Educomunicación, Realidad Aumentada, Realidad Virtual Diseño Gráfico. pmartin@centrosanisidoro.es, https://orcid.org/0000-0003-3055-7312

Juan Pablo Micaletto Belda es Doctor Interuniversitario en Comunicación (Universidades de Cádiz, Huelva, Málaga y Sevilla). Profesor responsable de las asignaturas Fundamentos de la Comunicación Persuasiva, Marketing, Teoría y Estructura de la Comunicación Digital y Técnicas de Investigación en Comunicación en el Centro Universitario San Isidoro de la Universidad Pablo de Olavide. Líneas de investigación: Comunicación, Publicidad, Comunicación Institucional.jmicaletto @centrosanisidoro.es, http://orcid.org/0000-0002-5424-6968
} 
have realized its storytelling potential. The objective is to test the compatibility of AR as a resource for advertising campaigns in RRSS supported by advergames with a transmedia strategy. The methodology is based on a triangulation whose vertices comprise a case study, a discourse analysis and a focus group (FG). The results derive from the analysis of two emblematic actions embedded in TikTok, a social network of exponential growth among the generation $z$. The campaigns under review are "WeStart" by Ma French Bank's and "You're On" by Ray Ban's. A series of reflections are brought to discussion regarding the advantages and peculiarities of integrating these strategies as an advertising story. As general conclusions, generation z seems to be called to adopt immersion as something proper to their social modes and cybercultural iconography, including this premise to transmedia advertising. In addition, AR advergames in social media find in transmedia a catalyst to reach their maximum performance.

Keywords: expanded advertising; augmented reality; transmedia; advertainment; advergaming.

\section{Introducción}

Las TIC en todas sus variantes, incluidas las RMe, calan e impulsan a la sociedad de manera indeleble. La comunicación, como ente ubicuo y líquido (Bauman, 2015), tanto en su rama periodística (Azkunaga-García et al., 2019) como publicitaria (Bajaña-Mendieta et al., 2018) se retroalimenta de esta tesitura. En un contexto caracterizado por la mediamorfosis informativa (De-Lara-González y Arias-Robles, 2017), la publicidad es una de las manifestaciones más destacadas y abiertas a la innovación. Si asumimos las palabras de Kotler (visto en Aguilera-Moyano y Baños-González, 2017), las técnicas tradicionales han perdido eficacia hace tiempo. El hecho redunda en que esta rama dependiente del marketing (Gómez-Nieto, 2017) busca incesantemente nuevos canales que le permitan calar entre los consumidores de manera eficaz y personalizada. La cuestión toma relevancia entre las nuevas generaciones, cuyas gramáticas giran de forma nativa en torno a los ciber-relatos. El branded content y el transmedia (Jenkins, 2010; Alberich-Pascual y Gómez-Pérez, 2017) llevan tiempo demostrando que aquellas acciones promocionales que se acogen a estas maneras de operar logran resultados positivos. Es en esta convergencia interdisciplinar donde tecnologías emergentes como la RA hibridan en narrativas complejas a ser tomadas en consideración y, en consecuencia, a ser escrutadas. Campos afines como el periodismo gozan de estudios que evalúan su compatibilidad con las RMe (Colussi y Assunção, 2020; Martín-Ramallal, 2020a). No ocurre de manera equitativa con la publicidad. Dada la frugalidad endémica en este campo del conocimiento, es imprescindible paliar el vacío epistemológico que arrastra esta tecnología de poderosa discursividad llamada a eclosionar de forma generalizada.

Las RRSS comienzan a despuntar como el escaparate idóneo para este tipo de acciones promocionales. Los centennials (Southgate, 2017) o generación z (Madden, 2017), han crecido a la par que estos espacios de socialización se han ido desarrollando. Al delimitar el rango de edad de este grupo no existe un consenso claro, pero el estudio asume que son aquellos nacidos entre 1994 y 2010 . Con altas capacitaciones tecnológicas y plenamente integrados de manera innata en su papel de prosumidor 2.0 (Aparici-Marino y García-Marín, 2018), han encontrado en TikTok la red propia de su generación (Tamara-Quiroz, 2020), igual que lo fue en su día Facebook para los millennials (Sabate et al., 2014). Su crecimiento explosivo entre los smartphones de los jóvenes (Vitelar, 2019) es muestra de ello. Su éxito se debe principalmente a la innovadora fórmula prosumer basada en vídeos cortos, aleatorios y verticales (Ryan, 2018), en filtros (incluidos los RA), en la música- coreografías, en el humor y en los retos. Entornos competidores como Snapchat (Hawker \& Cara, 2018) ya contaban con estas facultades, sin embargo, la red china ha sintetizado estos elementos lo que aporta un formato interactivo y de creación 2.0 inédito que ha calado de forma decidida entre la generación $z$. Este ciberespacio ha encontrado en los vídeos cortos verticales, la aleatoriedad, los minijuegos, los efectos multimedia y la música su razón de ser. Otra de sus funcionalidades intrínsecas, se halla en 
las RMe (Sidorenko-Bautista et al., 2020), incluyendo la RA, las cuales se aplican comúnmente con el carácter lúdico que caracteriza la app. Ante la evidencia, los anunciantes han puesto el foco en sus potencialidades para comenzar a desarrollar campañas de advergaming inmersivo de base transmedia (Méndiz-Noguero, 2012). Es por ello que se puede considerar esta RRSS como una plataforma ideal para analizar dicho discurso TIC encuadrado dentro de la denominada publicidad expandida, es decir, aquella que recurre a la RA (Martí-Parreño, 2011).

Expuesto lo anterior, los desarrollos de advergaming RA objeto de estudio serán WeStart de Ma French Bank y You're On de Ray Ban. Ambas propuestas demostrarán, una vez cotejadas bajo el prisma analítico adoptado, que disponen de elementos reiterativos que permitirán extraer conclusiones generales lo que posibilitará explicar parte de este fenómeno hipercultural.

\section{Materiales}

\subsection{La publicidad y el transmedia como conceptos afines}

La publicidad, afectada por el darwinismo digital (Hidalgo-Marí y Segarra-Saavedra, 2019, p.104), busca incesantemente innovadoras vías de acceso a la creciente diversidad de públicos objetivos. Las TIC, innegables motores de la modernidad líquida (Bauman, 2015), ofrecen cada día inesperadas formas de interrelación. La promoción se perfila como una actividad comunicacional vinculada irrefutablemente al marketing, por lo que se ve subordinada a una búsqueda incesante de la eficacia y la eficiencia (Gómez-Nieto, 2017). Dando rigor a esta premisa, la American Marketing Association -AMA- (2021) expone que:

El marketing es el proceso de identificar las necesidades del cliente y determinar la mejor manera de satisfacer esas necesidades. En cambio, la publicidad es el ejercicio de promocionar una empresa y sus productos o servicios a través de canales de pago. En otras palabras, la publicidad es un componente del marketing.

Retotrayendo, la aparición del e-bussines, y por consiguiente el e-marketing, implicó la necesidad de adaptar el diseño y la publicidad a un nuevo lenguaje digital (Straus \& Frost, 2016). Más allá de la lógica capitalista, la publicidad del s.XXI se encuentra en un consabido ciclo de regeneración por influencia de las TIC y del citado darwinismo digital. A este proceso contribuye la fragmentación de las audiencias. La dispersión deriva en la infinidad de formatos existentes, en su supuesta diversidad y en las múltiples vías de acceso a los contenidos culturales. Por ende, los gustos y hábitos de consumo de los públicos objetivos están más acotados que nunca a la hora plantear cualquier campaña.

Otra peculiaridad se halla en que el consumidor-público objetivo ha pasado a ser parte activa e irrenunciable del proceso publicitario. Como mantiene Sidorenko-Bautista et al. (2018, p.21), "la comunicación de uno-a-muchos, característica del siglo XX, ha dado paso al modelo de muchos-a-muchos en el que el receptor pasivo se convierte también en emisor y adquiere plena capacidad para desarrollar". El público participa de cuatro maneras según Jenkins et al., (2015, p.26). Esto es: generando contenido, redistribuyéndolo, remarcándolo o remezclándolo. En un contexto publicitario saturado y ultracompetitivo, agencias y anunciantes reclaman estas formas de alcanzar e impactar a sus públicos de referencia. Para combatir la evidente intoxicación publicitaria, aparece como remedio todas estas narrativas transmedia, un conjunto de técnicas retóricas aplicadas a la cibersociedad para lograr la máxima pregnancia de las acciones promocionales (Scolari, 2013; Alberich-Pascual y Gómez-Pérez, 2017; Sánchez-Mesa, 2019). Con todo esto, el estudio se circunscribe a la propuesta de transmedia de Sidorenko-Bautista et. al (2018, p.26):

Una historia que se narra a través de distintos fragmentos que, además de estar relacionados entre sí, permiten su consumo autónomo, se distribuyen aprovechando las características comunicativas de cada 
lenguaje, medio o plataforma y buscan la interacción con los usuarios para aumentar su difusión y aportar nuevos contenidos.

Siguiendo con la contextualización de un sector en efervescencia, se hace necesario remarcar en qué consiste la misión de la publicidad. Kotler y Amstrong (2013, p.470) definen esta área como "cualquier forma pagada de presentación y promoción no personal de ideas, bienes o servicios, que lleva a cabo un patrocinador identificado". Describir este campo es complejo por la citada metamorfosis en la que se ve inmerso (Gómez-Nieto y Tapia-Frade, 2016, p.394). Pensando que el objeto de estudio aborda un relato digital puntero y el canal de difusión a observar es una RRSS disruptiva, es irrefutable recurrir a un concepto de publicidad que englobe ambas realidades de la postmodernidad. Acorde a estos postulados, será apropiada la concepción de Kerr y Richards, (2020, p.25), pues entienden la necesidad de redefinir el concepto dadas las circunstancias ciber-sociales en las que se ve mediado. Por consiguiente:

La publicidad es la comunicación entre los medios pagados, los medios propios y los ganados, activada por una marca reconocible/identificable y con la intención de persuadir al consumidor para que realice tantos cambios cognitivos, afectivos o de comportamiento, ahora o en el futuro.

De esta propuesta se desprende la constante evolución a la que se ve sometido el acto publicitario, primando actualmente la construcción de relatos complejos y fragmentados centrados absolutamente en el sujeto-receptor. Esta entidad será el protagonista indiscutible del proceso y está destinado a ser parte activa en la propagabilidad (Jenkins et al., 2015) del mensaje mediante los nuevos canales TIC 2.0. En un espacio social cada vez más sesgado por las numerosas y difícilmente abarcables ventanas a la información, la RA en sintonía con los advergames, o juegos publicitarios, se abre como una nueva posibilidad para los públicos en aquello que será denominado como publicidad expandida.

\subsection{RA y publicidad expandida como entes simbióticos}

De las distintas RMe, la RA es la que tiene mayores tasas de aceptación porque no requiere dispositivos específicos como sí ocurre con la RV. Con un simple smartphone es posible disfrutar de experiencias de gran calidad. Esta narrativa digital, pese a la percepción generalizada de que se sustenta en una tecnología recién creada, tiene cierto recorrido. Tanto es así, que la definición más extendida y citada es la gestada por Azuma en 1997. Para el investigador la RA debe tener tres características irrenunciables para poder catalogarse como tal: combinar elementos reales y virtuales (digitales); la interacción debe darse en tiempo real; se ha de integrar en el entorno real mediante tres dimensiones. Básicamente, superpone una capa de información digital enriquecida, principalmente mediante dispositivos ubicuos y especialmente de índole visual, aunque también puede ser sonora o háptica, reconfigurando el espacio inmediato. Azuma (1997, p.2) manifiesta que:

La RA permite al usuario ver el mundo real con objetos virtuales superpuestos o añadidos formando en conjunto una composición con el mundo real. Por lo tanto, la RA complementa la realidad en lugar de reemplazarla completamente.

De forma más reciente, es admitida la definición de Cabero-Almenara y Pérez-Díez (2018, p.130):

La RA es una realidad mixta, integrada en tiempo real, que posee una diversidad de capas de información digital en distintos formatos (textos, URL, vídeos...), que es interactiva, y que mediante su utilización enriquecemos o alteramos la información de la realidad.

En consecuencia, recreaciones como las realizadas por algunos medios de comunicación, especialmente en lo que se refiere a informativos (Azkunaga-García et al., 2019), no son relatos inmersivos plenos de esta tipología, pues les falta alguno de los elementos definitorios, tales como la sincronía temporal-espacial. 
Por el contrario, la RA puede cohabitar en armonía a través de la publicidad expandida pues, a la espera de las gafas AR (Perry, 2021), el smartphone es el dispositivo ideal para generar estas historias, especialmente entre los jóvenes (Viñals-Blanco, 2016). Desde que Snapchat integrara en 2012 los primeros filtros basados en estos recursos, tanto los avances como su aceptación han ido a más constantemente. La relación es recíproca, pues la RA encuentra en la publicidad en RRSS el mejor escenario en el que poder darse a conocer y normalizar su uso. Para Martí-Parreño (2011, p.34), las narrativas transmedia disponen de dos ventajas significativas: incrementan la relevancia de las comunicaciones y se adaptan a las circunstancias concretas del usuario. Partiendo de estas consideraciones, resulta manifiesto que este discurso se ajusta a la visión de espacios con la misma filosofía y encuadre que TikTok.

\subsection{RRSS y TikTok, ecosistema natural para la RA publicitaria}

La RA ha dejado de ser una promesa discursiva superando la fase de expectativas (Gartner, 2018) para integrarse, de facto, en las RRSS lejos de visiones futuristas. Espacios como Facebook o especialmente aquellos que hacen desde su génesis de la imagen y el smartphone su razón de ser, como son Instagram o TikTok, implementan hace tiempo reclamos RMe. Una muestra evidente son los filtros faciales y demás artificios de superposición RA, incluidos aquellos con elementos de marca (Phua \& Kim, 2018). Los principales consumidores de este proceso de transcodificación personal son las nuevas generaciones, que perciben estos efectos como algo implícito y natural a las RRSS. Son fruto de la remediación del selfie, de la RA y del concepto tradicional de máscara (Jiménez y Marinas, 2020, p.130). En el caso concreto de TikTok, los usuarios, según Zou y Wang (2019), están motivados por la búsqueda de entretenimiento y autoexpresión, la obtención de beneficios y el consumo de ciertos productos básicos, por conectarse a las tendencias del momento y por la búsqueda de relaciones sociales de diversa índole.

Basándonos en los argumentos de Kotler y Armstrong (2013), las marcas se conforman en su núcleo de seis niveles de significado: atributos, beneficios, usuario, valores, cultura, y personalidad, siendo los de mayor durabilidad comunicacional los tres últimos. Con esta premisa, la publicidad nativa (Maestro-Espínola et al., 2019) de TikTok con base RA dispone de todas las características para respaldar el mencionado ideario. En el entorno actual, se hace necesario para las empresas tener presencia en las distintas RRSS (Rebolledo-Bueno, 2017) y tanto la RA como TikTok pueden ser oportunidades para ofrecer marketing experiencial de calidad (Baños-González y de Aguilera-Moyano, 2017, p.4) pues abren las puertas a los estratos más jóvenes de la población. Esta red social, salpicada por la polémica (Tamara-Quiroz, 2020), ha vivido un crecimiento sin precedentes. Evolución de la red Musical.ly, desde su aparición en China en 2018, su expansión ha sido incontestable hasta superar en poco más de dos años los 1500 millones de suscriptores activos, cifras desconocidas hasta el momento en lo que parecía un mercado saturado. Este espacio está reescribiendo lo que son las interacciones entre los más jóvenes (Herrman, 2019). Uno de los focos de atracción en los que se ha basado es su original forma de tratar la generación y consumo de vídeos entre sus miembros (Omar \& Dequan, 2020), especialmente y de forma protagónica mediante el smartphone. Aloja como estímulos de dicha explosión elementos propios más allá de invocar al homo videns (Sartori, 2012). Uno de ellos son las distintas y variadas opciones de ludificación de la RA, algo también inherente al advergaming inmersivo (Martín-Ramallal, 2020b). Sin ser su enfoque principal, desde sus albores cuenta con filtros de esta tipología. No son algo nuevo, pues ya se podían disfrutar en los espacios precedentes, pero en este caso se han integrado de manera natural pues el vídeo es su esencia, por lo que la comunión entre ambos lenguajes es fluida. TikTok ofrece contenidos que, por su producción habitualmente amateur, son vistos como algo familiar y cercano. Esta aptitud proactiva hacia la inmersión enlaza perfectamente con la RA, pues pretende brindar, más allá de la sofisticación que implica, una interacción transparente. Un ejemplo de su interés por las RMe es el filtro RA que lanza para el sensor LiDAR con el fin de celebrar la entrada del año 2021 (Araque, 2021). Otra 
evidencia singular es que TikTok cuenta con Effector, una herramienta RA para que los prosumers puedan hacer sus efectos personalizados. Se ha de aclarar que el software no está disponible por el momento en todas las regiones de acción de la RRSS, pues está en fase de desarrollo.

En línea con lo expuesto, no se ha de olvidar lo que comentan Baños-González y Aguilera-Moyano (2017, p.11):

Las motivaciones de los usuarios para seguir a una marca en RRSS se basan, fundamentalmente, en atributos hedonísticos y en una recompensa que se debe materializar en una propuesta de valor coherente con los valores y atributos de cada marca.

TikTok denota desde su identidad visual su inclinación hacia los relatos audiovisuales y tridimensionales, tal y como demuestra su logotipo, con inspiración en la estereoscopía y en una estética basada en el anaglifo. Este tipo de identidades también son susceptibles de ser entes transmediales (Mut-Camacho y Miquel-Segarra, 2019). En el contexto promocional, la compañía defiende que las marcas que recurren a sus servicios logran notoriedad y un gran engagement entre sus públicos. El que los usuarios puedan controlar la interacción, incluida la RA, insufla implicación con la campaña de advergame, reconfigurándose estos sujetos en abanderados del anunciante.

La red dispone de TikTok for Business (2021) (véase enlace), espacio donde se sitúan campañas y piezas inspiracionales, a la par que posibilita la contratación del servicio publicitario. Pone a disposición de las marcas AR Branded Effects, un conjunto de recursos RA para generar contenidos, superando las capacidades de otras RRSS. Como no podía ser de otra manera, cuentan con sus propias herramientas analíticas (TikTok Pixel). Otro instrumento creativo es Gamified Branded Effects. Estas acciones de advergaming posibilitan a los públicos objetivos interactuar con las marcas de forma competitiva, creando un fuerte vínculo. Para desarrollar un filtro de marca RA hay que acudir, por el momento, a los servicios de la compañía o a los de terceros certificados como Poplar Studio (véase enlace).

Un elemento clave de TikTok en la órbita con la publicidad 2.0 (Durán-Medina, 2014) son los retos o challenges, cómo podría ser realizar una coreografía, que también son usados con fines publicitarios. Uno de los fundamentos conceptuales es la música, cuyos ritmos sirven habitualmente como patrón para la edición del vídeo, para realizar una coreografía o ilustrar de forma sonora un challenge o cualquier otro tipo de demostración o sketch humorístico. En este sentido, dispone de una amplísima biblioteca sonora de libre acceso, lo que ha pasado a convertirse en una ventaja competitiva y un reclamo para los usuarios más creativos.

Todas estas características de TikTok y su atractivo entre las nuevas generaciones no han pasado desapercibidas entre los anunciantes, los cuales han visto en los advergames inmersivos un canal para llegar de forma eficaz a estos segmentos.

\section{Objetivos}

El objetivo general de este trabajo de investigación es analizar desde una óptica multidisciplinar el empleo y eficacia en el discurso publicitario de la RA a través de advergames inmersivos para RRSS, y cómo ello trae consigo el fenómeno de la publicidad expandida, la cual funciona de manera optimizada en contextos transmedia.

Para la correcta consecución del principal objetivo expuesto, se marcarán como metas subordinadas los siguientes objetivos específicos:

1. Fijar las características y las posibilidades de aplicar la RA como instrumento para la creación de campañas de publicidad transmedia. 
2. Examinar el uso y la aplicación del advergaming inmersivo en la publicidad expandida como herramienta para campañas transmedia en RRSS.

3. Interconectar distintos ámbitos de estudio (interacción, diseño, publicidad, advertainment, advergaming, inmersión, etc.) y configurar un único marco multidisciplinar que constituya una herramienta de investigación eficaz y útil para el análisis de la publicidad en RRSS basada en RA.

A4. nalizar dos casos paradigmáticos de advergames RA nativos en la red social TikTok con eje transmedia que permitan identificar sus rasgos y elementos más frecuentes a partir del marco multidisciplinar previamente constituido.

\section{Metodología}

Aclarados los objetivos, la investigación parte del método deductivo desde el cual se han fijado los conceptos clave y la teoría pertinente en la fase de materiales. Con perspectiva holística, se asume una visión explicativa-descriptiva respecto a las condiciones en las que se manifiesta la RA publicitaria en RRSS. No se puede obviar la implementación en el estudio de un enfoque exploratorio dada la emergencia de estas narrativas RMe y de la propia red TikTok (Bernal, 2010). El motivo que ha llevado a observar este espacio digital es la abrupta y profunda irrupción que ha tenido entre los estratos poblacionales más jóvenes.

De forma particular, la investigación se basa en un modelo-artilugio de análisis propio para la RA publicitaria, ya que no existe un esquema para tal fin suficientemente contrastado. De modo específico, se conforma la metodología mediante una triangulación metodológica cuyos vértices de observación los ocupan un estudio de caso, un análisis del discurso y un FG (véase Figura 1). Este instrumento multifocal implica que en la zona de confluencia es donde se generará conocimiento contrastado.

Figura 1. Triangulación de herramientas metodológicas para la investigación

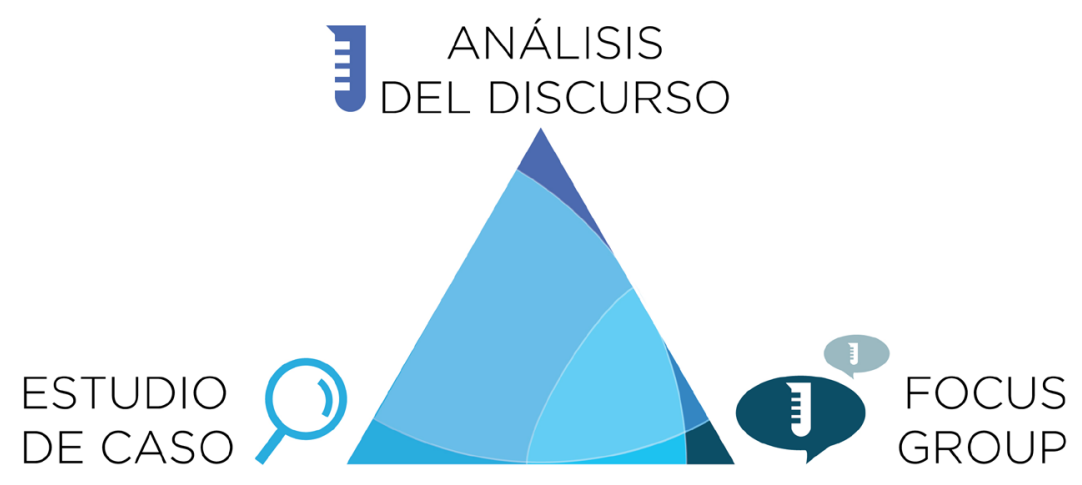

Fuente: Elaboración propia

Subordinada a estos sistemas, se realiza una labor de teorización a partir de la revisión bibliográfica relativa al tema de la publicidad expandida, la RA y las RRSS. Como defienden Díaz-Valladares y Peñazona-Yañez (2015, p.256), este enfoque "permite entender cada hecho particular en su articulación con totalidad social en un momento histórico concreto, a la vez que se adquiere una visión crítica y creadora de la práctica social".

Al ser áreas supuestamente dispares, los recursos referenciales se abordan con una óptica multidisciplinar, lo que al ser aplicado al corpus de la investigación implica que adquiera un carácter aproxi- 
mado al de un estado del arte fenoménico. Dentro de este rango de la fase descriptiva, el propio sitio corporativo aporta información la cual será plasmada ya que la adquiere el rango de fuente primaria.

Para completar el estudio, se ha implementado un instrumento hermenéutico basado en el estudio de caso múltiple (Yin, 2017), los cuales pasan a ser paradigmáticos dada su singularidad y carácter referencial. Como la propia etimología revela, se examinan más de un caso, lo que permitirá comparar y extraer desde la convergencia conclusiones generales. Este proceder implica robustez y garantías al estudio. Para su selección se ha elaborado un exhaustivo trabajo de campo a nivel internacional, tanto en Internet como en la propia TiKTok (véase Inspiraciones en la web), ya que dentro de las fronteras españolas las promociones de este tipo escasean. Se ha detectado que la RA va abriéndose paso, tanto entre los consumidores como entre los anunciantes, lo que permite observar el fenómeno en su conjunto a través de las campañas WeStart de Ma French Bank y You're On de Ray Ban. Dichas acciones serán contempladas aplicando algunas cuestiones del modelo de estudio de la RA para la educación de Cavero-Almenara y Pérez-Díez (2018), pero ajustándose libremente al marco publicitario. La selección de estos objetos materiales surge a raíz del trabajo de campo. El universo muestral de la publicidad inmersiva RA en RRSS, por el momento, resulta muy limitado, indiferentemente del espacio físico o temporal en que se aprecie el estudio. A consecuencia directa de esta tesitura, se han estudiado los casos mencionados, llegándose a cotejar campañas sitas fuera del contexto analítico-geográfico de los autores. He aquí una evidencia más de la novedad, emergencia y singularidad del tema que ocupa el texto.

Por último, se ha puesto en valor como herramienta un análisis colectivo e individual del discurso visual e interactivo. En el segundo caso se han convocado dos FG, uno de expertos (A) y otro de usuarios de la red (Z). Las fases del FG fueron planificadas acorde a las necesidades específicas de la investigación. Se siguieron unos pasos concretos basados en modelos estandarizados en lo que refiere a pruebas grupales (Bernal, 2010) -véase Figura 2-.

Figura 2. Fases constituyentes del FG

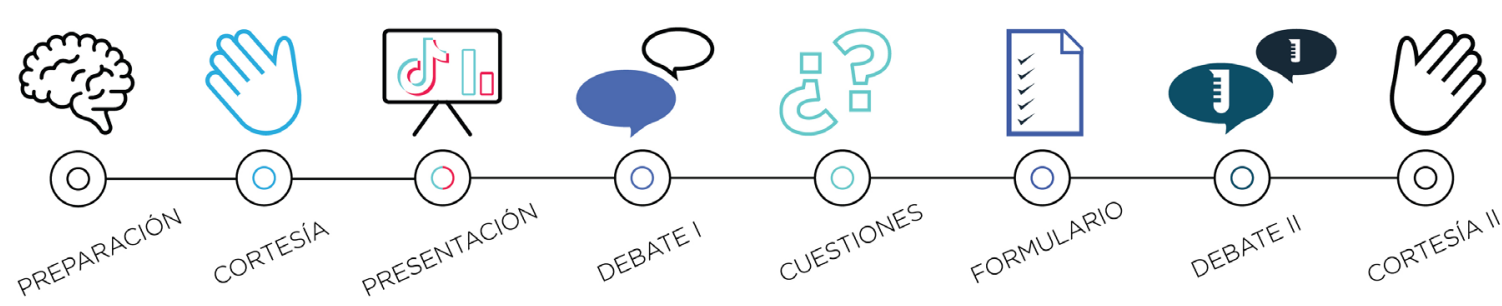

Fuente: Elaboración propia

Para reclutar a los miembros del Grupo A se ha considerado que debían tener una trayectoria contrastada en el campo de la investigación en comunicación digital y publicidad. En su devenir profesional suman en su conjunto experiencia docente y profesional en el sector de la promoción y del marketing, así como recorrido en investigación científica en Ciencias de la Comunicación, lo que justifica su candidatura. Tres de los participantes (dos autores y un participante forman parte del grupo de investigación Sociedad Digital y Creatividad del Centro Universitario San Isidoro (Sevilla, España). El resto de integrantes fue invitado en relación a sus rasgos sociales, profesionales y/o carrera en investigación y forman parte de la esfera de la comunicación de Andalucía (España).

Para ajustar el perfil sociodemográfico de la segunda muestra (Grupo Z), se invoca al usuario tipo de TikTok, es decir, principalmente integrantes de la generación $z$, por lo que se asumen todas las peculiaridades del mismo (Seemiller \& Grace, 2018). Con edades comprendidas entre los 22 y 25 años, otra característica definitoria es que cursan estudios en Comunicación Digital, lo que les con- 
fiere cierto perfil heurístico. El texto, sin pretensiones estadísticas, asume en parte naturaleza divulgativa, para lo que integra en el FG un cuestionario libre de Likert basado en preguntas dicotómicas. Integrar una innovación de esta naturaleza en el dispositivo de investigación permite visualizar la postura general de los integrantes de cada grupo como si fuesen entidades monolíticas. En la fase de resultados se amplía la información sobre los procedimientos invitando a una óptima transferencia del conocimiento.

Acotado el universo bibliográfico de la publicidad RA, se detecta que el análisis del discurso es la forma de abordar el tema más habitual. Se regirá por los siguientes parámetros connotativos respecto a sus valores de pertinencia: formato, color, legibilidad y tipografías, imagen, dinamismo e interacción (véase Figura 3). Se sitúa como referencia para la observación los estudios de Gamonal-Arroyo (2012) desde la faceta visual del objeto a análisis, obviando el abordaje retórico.

Figura 3. Ítems connotativos constituyentes del análisis del discurso y del FG

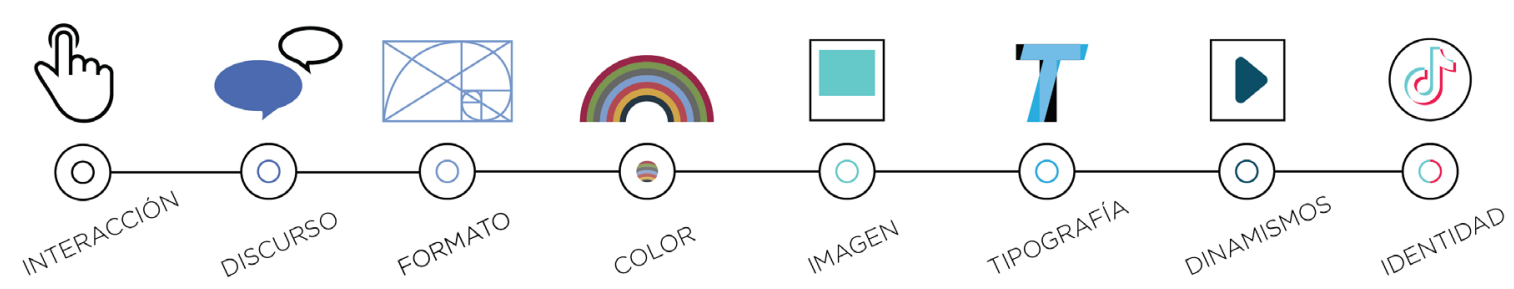

Fuente: Elaboración propia

\section{Resultados}

\subsection{Estudios de caso a partir de análisis del discurso}

\subsubsection{Caso 1. Ma French Bank WeStart}

El primero de los casos corresponde a la campaña WeStart de advergaming RA promovida por el banco francés Ma French Bank. La vocación de la entidad es principalmente online y su plataforma de difusión está estructurada $100 \%$ para smartphones. La promoción inmersiva transmedia lanzaba el producto WeStart y aspiraba captar a los ahorradores más jóvenes de la generación $z$. El otro concepto de comunicación residía en unir a padres, adolescentes y a la marca en un espacio común. En palabras de la institución: "queríamos diseñar una campaña atractiva para los adolescentes y tranquilizadora para los padres con el fin de promover la aplicación WeStart en una zona de confianza intergeneracional" (Beldico-Pachot, 2021).

Con creatividad de Razorfish Agency y Publicis Sapient, uno de los principales engranajes transmedia es el desafío para TikTok bajo el hashtag \#WeStartChallenge. Será el primer banco francés que apueste por esta plataforma, lo que le posiciona por afinidad en la cúspide del short list sectorial entre los más jóvenes. Planteada en el marco francés durante la semana previa a las navidades de 2020, y con una duración de siete días, ofrecía como reclamo una codiciada consola PlayStation 5 para aquel que lograse la mayor puntuación. Otro elemento para captar la atención lo constituyó contar con la colaboración de creadores tales como@enzotaistoi,@powerpoussino@yofunders. Los influencers realizaron las habituales funciones de embajadores de marca, así como la de explicar la mecánica del advergame mediante vídeos demostrativos. 
El juego RA consiste en conseguir la máxima puntuación en un tiempo de sesenta segundos. La trama recurre a un tono asertivo y directo con el lenguaje y modos de los jóvenes, constatando que se intenta transmitir sus valores característicos sin artificios. La mecánica, diégesis e iconografía son de sobra conocidos, pues se acude a la estética pixel art y a títulos como Space Invaders (1978) (véase Figura 4). Es llamativo que los colores del advergame son los mismos que los de la identidad visual del banco. El desarrollo estriba en capturar los máximos puntos-monedas posibles en la cuenta del jugador mediante el uso de la tarjeta del banco como mediador-puntero. Al desplazarse el usuario delante de la cámara, el teléfono captura dicho acto y la tarjeta se mueve al unísono, debiendo esquivar a los extraterrestres y recopilar los objetos que nos aporten extras. Conforme pasa el tiempo, más rápido caen los elementos con el consiguiente aumento en la dificultad. La narrativa fomenta el gasto inteligente de una forma divertida y cercana usando el lenguaje de los más jóvenes. Los ítems a recopilar son cosas deseadas por los adolescentes, como hamburguesas, zapatillas deportivas o mandos de videoconsola. Al acabar la partida sonará una melodía que recuerda claramente las máquinas árcades de los años 80 . Al final aparecerá la puntuación sobre una hucha cerdito, lo que deja claro que lo que se fomenta es el ahorro y no el consumo.

Figura 4. Jugador en TikTok del \#WeStartChallenge de Ma French Bank

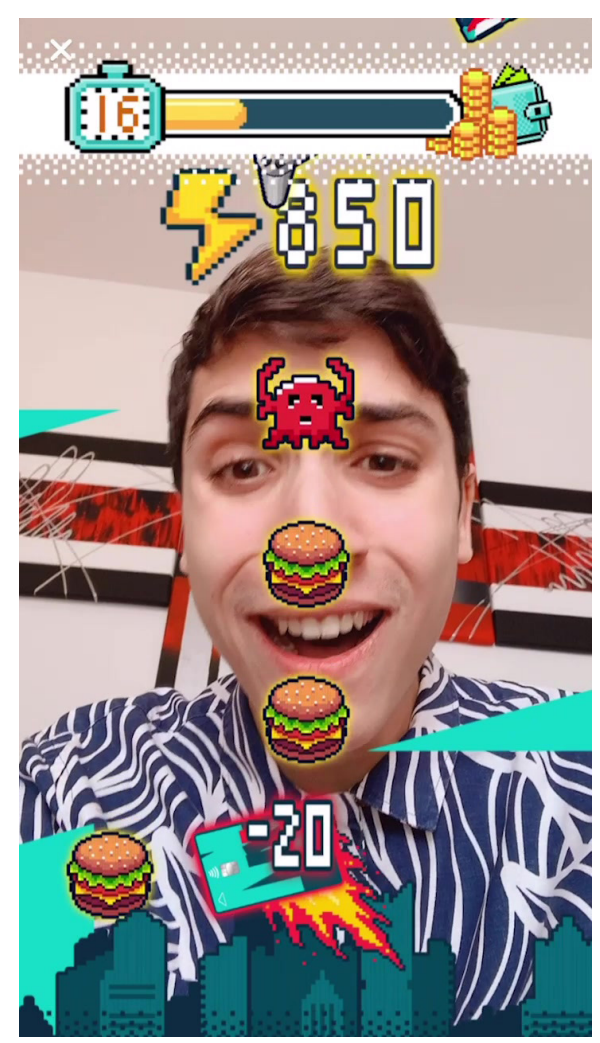

Fuente: TikTok (2021)

Respecto a la lógica transmedia, el anunciante despliega de forma previa una campaña paralela desde mediados de noviembre a través de sus RRSS y demás soportes de Internet. Para visualizar la acción y los lugares donde los interesados podían formalizar sus cuentas, varias oficinas de correos recibieron material promocional para ser personalizadas con la identidad de Ma French Bank (véase Figura 5). Pese a ser una marca vinculada a un sector tradicional como la banca, se inspira en el humor, en el juego y en el desafío 2.0. El reclamo es un vínculo hacia las nuevas generaciones que rompe la barrera reputacional que estos estratos poblacionales podrían tener en cuanto a las entidades financieras. En este sentido, el que un jugador se auto referencie dentro de la RA con la marca es 
algo positivo, pues se fija un lazo metafóricamente tangible. Una muestra del respeto que el banco muestra hacia los jóvenes se materializa en la gráfica que sitúa una franja que tapa los ojos de los modelos (véase Figura 3). Se quiere dejar claro que Ma French Bank no los trata como si fueran incoherentes o inmaduros, sino que los muchachos saben lo que quieren hacer con su dinero y hacia dónde se dirigen, por muy jóvenes que sean. La cartelería cuenta con una clara inspiración cibercultural. Las imágenes están fraccionadas con la disposición del logo de Ma Frech Bank, pero también evoca los encuadres fotográficos de los teléfonos móviles, así como su difusión en distintas RRSS.

Figura 5. Publicidad impresa de la campaña WeStart
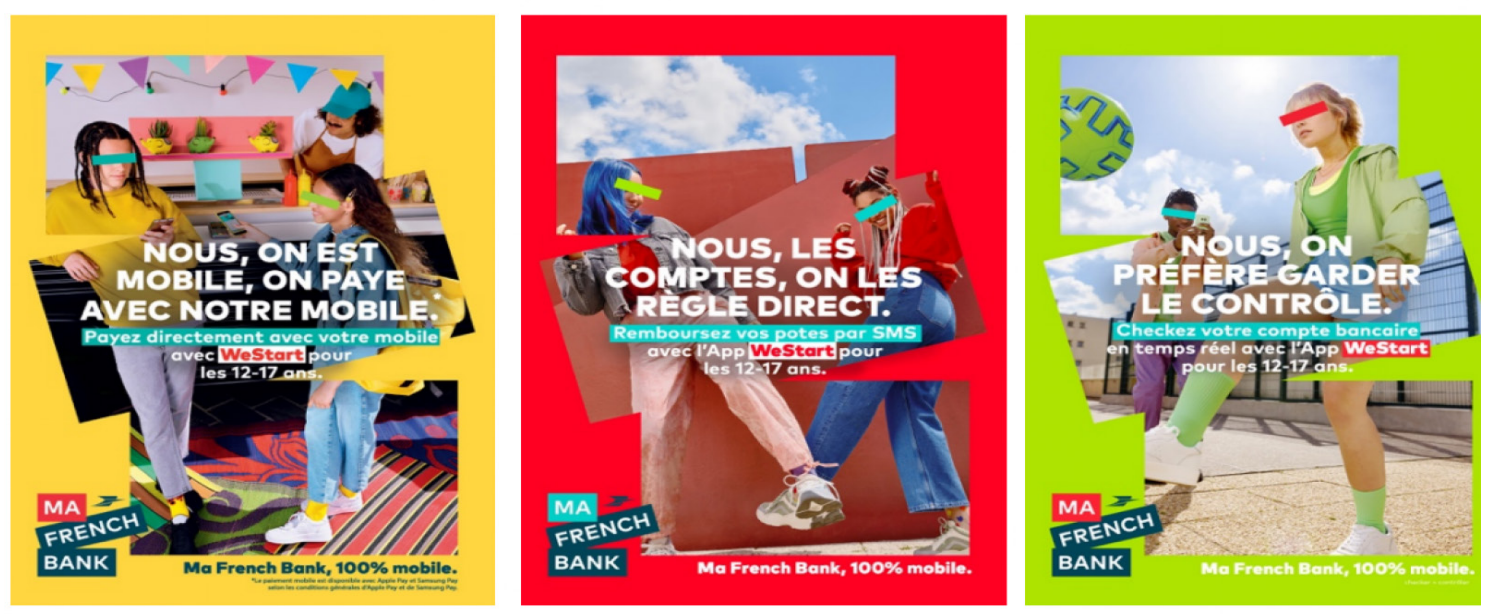

Fuente: Web oficial del Ma French Bank (2021)

Las cifras mostradas por la plataforma y por los anunciantes para una campaña de una semana de duración hablan por sí solas. 300 millones de visualizaciones, cien mil vídeo-partidas creadas con cuarenta y cinco mil jugadores únicos. Los contenidos fueron redifundidos en otras redes como YouTube o Instagram, ampliando considerablemente la propagabilidad de la iniciativa. La app y la web de TikTok ofrecen esta posibilidad de manera nativa, así como el código para implementar el audiovisual en cualquier web. Estas cifras evidencian el éxito al comprobar que el público objetivo eran jóvenes de entre doce y diecisiete años, un sector totalmente ajeno a los productos financieros. Este grupo social no es el más rentable para la banca, pero al crear lazos con sus clientes desde tan jóvenes e instruirlos en el manejo de la app de la entidad las relaciones posteriores con Ma French Bank serán muy fuertes y estrechas. La campaña se entiende como una decidida inversión a futuro. Si se visita la web, se aprecia que también se pretende captar la atención de los padres para que estos supervisen a sus hijos, por lo que se consolidan como un público objetivo colateral de decidida importancia.

\subsubsection{Caso 2. Ray Ban You're On}

Ray Ban es una compañía que se caracteriza por realizar campañas con vocación transmedia. Un ejemplo de su proceder pionero es la acción omnicanal $360^{\circ}$ You're On (¡Estás conectado! en español), difundida en noviembre de 2020 convirtiéndose en la primera de esta clase en Europa (España, Italia, Alemania y Reino Unido). La creatividad tiene como centro el pinball (véase Figura 7), juego icónico de tipo social que lleva implícitos valores cercanos a la juventud. La idea central era el relanzamiento de los modelos más tradicionales con un rediseño que permitía incluso la personalización de las monturas, lo que hace de estas gafas un producto ajustado a los nuevos tiempos. Una 
prueba de la filosofía transmedia de la iniciativa es la variedad de estilos gráficos que se diseñan según el soporte al que se enfoque -fotografía, ilustración u ocho bits- (véase Figura 6).

Figura 6. Gráfica Ray Ban You're On y cartelería PPV
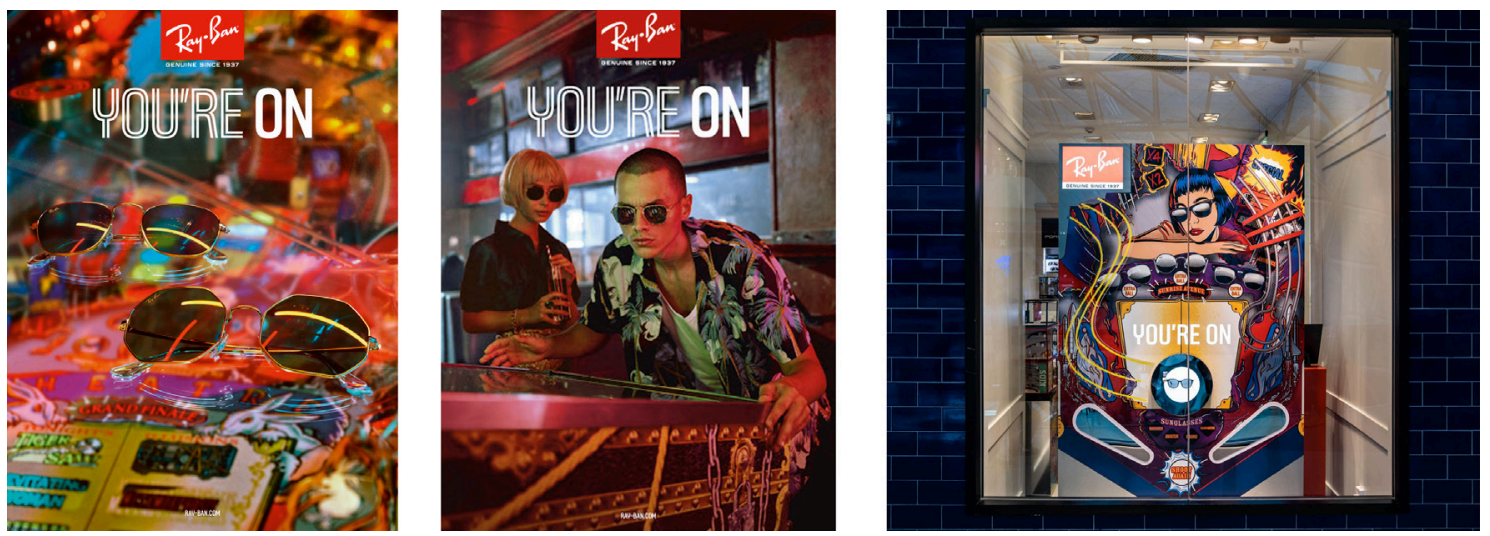

Fuente: Web oficial de Ray Ban y Moodie Davit Report (2021)

Acorde al eje creativo transmedia de contenido expandido, la acción de advergaming RA reincide en el pinball, siendo el nexo entre lo clásico de Ray Ban y la hipermodernidad 2.0 que acompaña la cosmovisión de las nuevas generaciones. Nuevamente el propio usuario se convierte en el elemento interactor pero esta vez con mayor complejidad. El jugador, portando virtualmente distintos modelos de las míticas gafas de la marca americana, moverá sus cejas para accionar los tacos de la máquina recreativa. Ha de evitar que caiga la bola mientras se suman puntos en un plazo determinado de un minuto (véase Figura 7). El que se porte las gafas virtualmente sirve para que el advergame se convierta en un probador 2.0, ya que dispone de la facultad de que los seguidores puedan opinar sobre si favorecen al jugador. Las tipografías, la línea de tiempo y demás iconos son los propios de un juego arcade clásico o de un flipper. Es mencionable que se resalta un botón amarillo con la opción de que cualquiera que vea la retransmisión pueda jugar al advergame RA.

Figura 7. Advergame Ray Ban You're On en TikTok
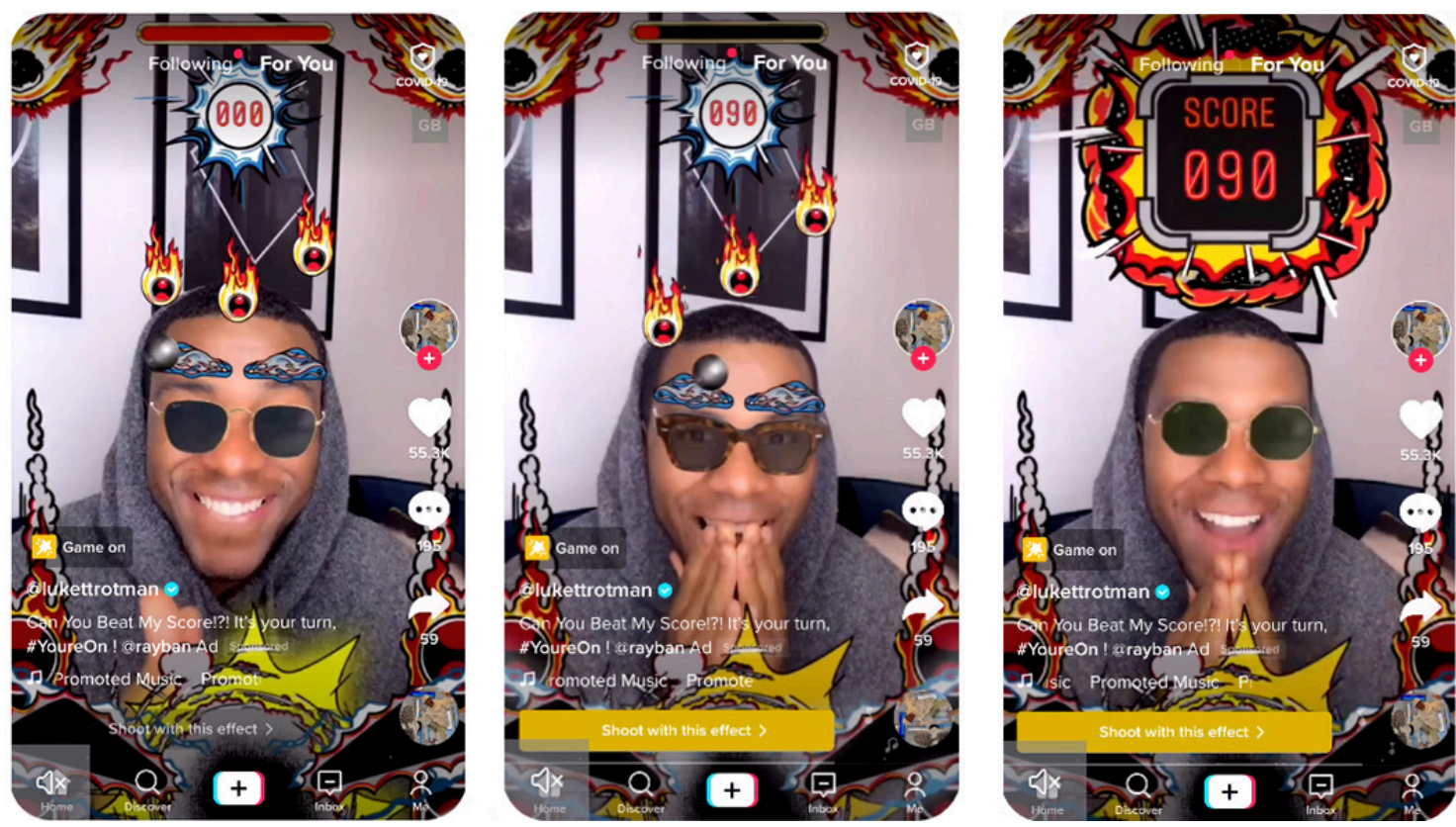

Fuente: Capturas de pantalla oficiales de TikTok 


\subsection{Resultados de casos confrontados al FG}

Pasada la descripción de los casos y la respectiva interpretación vehicular del análisis discursivo, el documento se encuentra en disposición de confrontar los resultados arrojados a través de la metodología de un doble FG. La prueba tuvo lugar sincrónicamente el 15 de marzo de 2021 en un entorno controlado situado en el Centro Universitario San Isidoro (Sevilla, España). Para el Grupo A se requirió la participación de siete expertos en comunicación digital y publicidad. Como se comentó, para constituir el Grupo $Z$ se solicitó la ayuda de siete integrantes de la generación $z$.

Se realizó, en primera instancia, una presentación pormenorizada por separado con todos los datos logrados hasta el momento por los autores. Se repartió a los miembros de ambos comités evaluadores un guión y material de trabajo conforme al modelo de Bernal (2010). Al final de esta primera fase, se les reunificó para poner en común el trabajo y unificar las aportaciones.

En este estadio del estudio, se tabulan los resultados (véase Tabla 1) donde es llamativo que los dos casos propuestos comparten datos afines en multitud de parámetros, dando a entender la idoneidad de la elección más allá de los límites del universo muestral. Las apreciaciones (preguntas) surgieron orgánicamente de ambos FG durante la fase del primer debate, y se las expuso a todos los participantes de nuevo en la fase final de la prueba a modo de diálogo colectivo (véase Figura 2). Los asistentes debían expresar sus niveles de conformidad a las preguntas de forma dicotómica, lo que se extrapoló a una escala de Likert de siete niveles, donde cero manifiesta total rechazo y siete una aprobación máxima. Antes de llegar a este contexto se generaron diez afirmaciones por consenso tras una ronda de preguntas y respuestas. El proceso dio lugar a aportes valiosos para el objeto de estudio. El realizar dicho cuestionario colectivamente le atribuye una visión holística y participativa. La Tabla 1 no pretende tener peso estadístico, sino dar forma gráfica a la opinión de los distintos grupos de trabajo y aclarar las heurísticas a debate de una forma sencilla y accesible. Entre los asistentes hubo bastante consenso a favor de este tipo de campañas pese a no existir relación personal ni profesional entre los sujetos de los dos grupos. Como se aprecia, la recepción de los casos de advergame inmersivos fue muy positiva.

Tabla 1. Respuestas dicotómicas de los sujetos relativas a las cuestiones derivadas de ambos FG

$$
\text { Grupo A Grupo Z }
$$

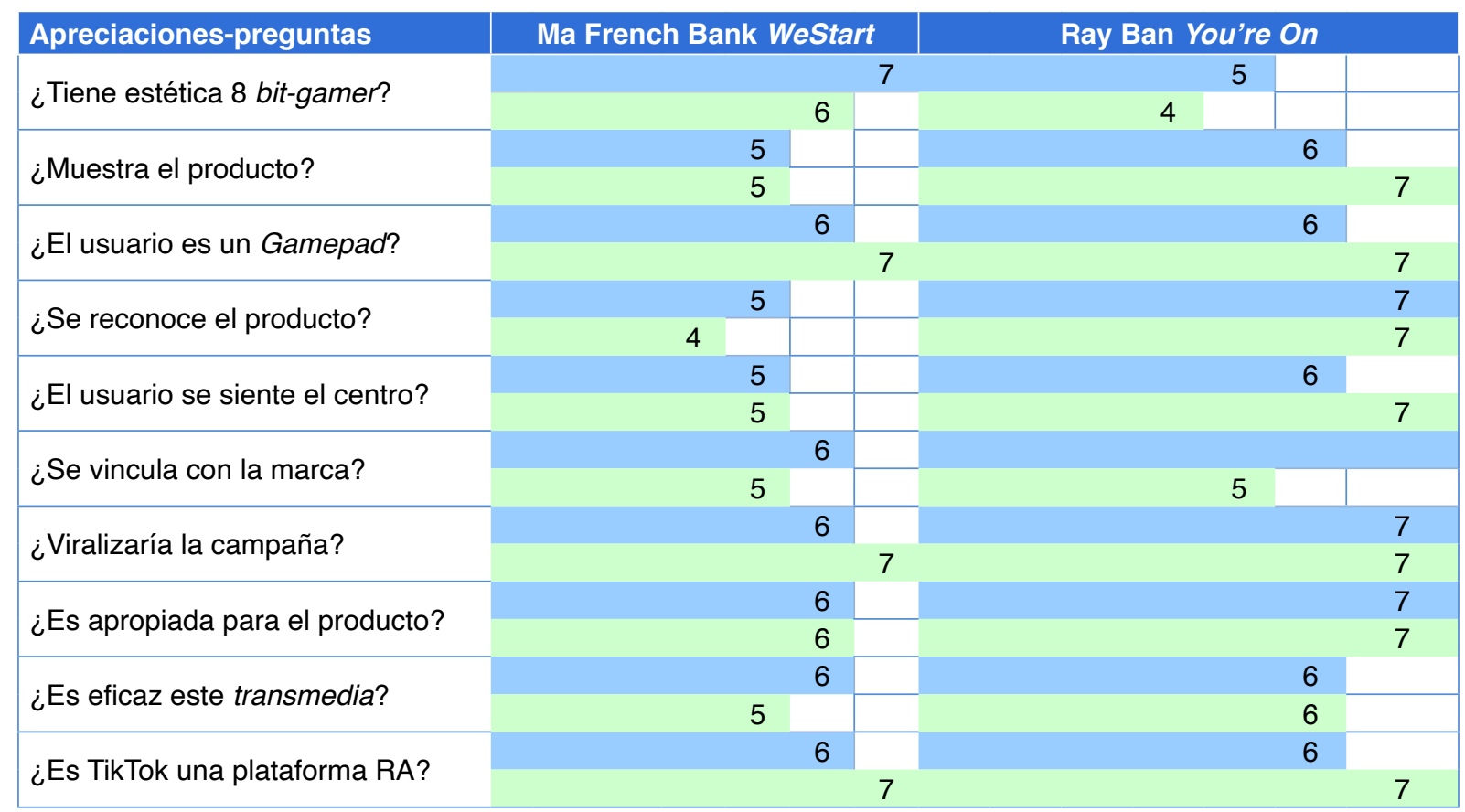

Fuente: Elaboración propia 
De dicha jornada se extrajeron una serie de propuestas epistemológicas de interés. Se ha de comentar por su trascendencia que, al ser interpelados, parte de los componentes del Grupo A reconocieron que la curva de aprendizaje de TikTok se les manifestó pronunciada al principio pues no habían tenido contacto intensivo con la red. El lenguaje interactivo y el amplísimo ideario audiovisual les resultaba ocasionalmente un discurso exógeno. Sin embargo, esto no ocurría con las campañas analizadas, las cuales se creía que eran sencillas de decodificar y apelaba a insights de amplio rango. En el Grupo $Z$ no se apreció en absoluto la circunstancia relativa al aprendizaje ya que todos eran usuarios habituales.

Desde el punto del diseño visual, los FG sirvieron para extraer que las tipografías empleadas en los dos casos son monoespaciadas, es decir, con el mismo ancho, algo peculiar relacionado con los orígenes de la informática. Los colores son saturados y muy limitados, con una paleta no superior a 32 tonalidades principales. La iconografía apelaba a recursos pop como la estética del cómic con iconografías tales como las líneas cinéticas. Así, parece ser útil recurrir a la visión estandarizada que se tiene de los videojuegos clásicos, algo que, más allá de la edad, ha pasado a ser cibercultura universal intergeneracional.

Otra cualidad considerable es la reconversión del cuerpo en ente interactor digital. Se interpreta que el simple reflejo del sujeto cala profundamente en la implicación con la marca. La coyuntura se convierte en una oportunidad para que los potenciales clientes prueben el producto a la par que muten en modelos referenciales para sus seguidores.

Gustó, y bastante, que el cuerpo del propio sujeto pasase a ser el gamepad (mando). Tanto la novedad como sentirse reflejado es algo que crea un fuerte lazo con la marca lo que se traduce en un profundo engagement. Los advergames RA en RRSS dan lugar a compromiso con la marca, y de esta complicidad se pasa a propagar la acción promocional en otras redes. También influye que el usuario se sienta el foco de todo esto. Es reseñable que el juego lograba mayores niveles de implicación según se usaran más elementos interactivos, como así demostró la campaña de Ray Ban que requería movimiento corporal y gesticulación facial.

Un dato destacable es que, pese a que muchos de los colaboradores no sentían atracción por los productos que se promocionaban, creían, a priori, que este tipo de campañas no eran apropiadas para servicios como un banco. Al observar el resultado cambiaron radicalmente de idea. Por tanto, los advergames RA en RRSS pueden servir para publicitar cualquier tipo de producto pues son apropiados y les insufla un discurso original y con gran potencial para el campo del marketing, especialmente entre la generación $z$.

Todos los asistentes (sin conocer los resultados objetivos en comunicación) estaban de acuerdo en que el advergame funciona mucho mejor como un engranaje dentro de la acción transmedia, pues la decodificación hubiera podido ser más complicada. Recomendaron integrar estas iniciativas en estrategias con enfoques plurales. El Grupo $Z$ se postuló firmemente con esta postura, especialmente con productos alejados de las nuevas generaciones como el servicio bancario estudiado.

Por último, TikTok demuestra que las RRSS son un portal idóneo para acciones publicitarias RA basadas en videojuegos. La interacción se percibe natural y el tono de la red es el apropiado dado su toque lúdico y el perfil del usuario que la caracteriza. La propuesta se manifiesta de forma contundente en el Grupo $Z$, donde se opina que con una creatividad bien plasmada, los advergames RA de esta naturaleza pueden promocionar cualquier servicio y producto entre los más jóvenes, pues la ven como algo propio de su generación.

\section{Discusión}

A tenor de lo expuesto, se confirma que el estudio parece contribuir empíricamente a la literatura existente sobre la gestión de estrategias de marketing RA para la participación del consumidor en 
los sitios de RRSS. Derivada de la fase analítica y de resultados, la investigación ha arrojado una serie de ventajas, así como consideraciones del uso de advergames RA en RRSS como TikTok como instrumento de branded content y para la publicidad transmedia.

\subsection{Ventajas generales y consideraciones del advergaming en RRSS}

A continuación, se recogen las principales aportaciones y revelaciones consecuencia directa del FG a modo de ventajas y consideraciones materializadas según criterios de relevancia. No se reiteran aquellas posiciones reveladas directamente en el FG.

En primera instancia, hacer partícipe y protagonista al público objetivo mediante la RA se antoja algo beneficioso para los anunciantes. La naturalidad y frescura de los prosumers sirve de contrapeso para marcas que, por área de acción, se les presuponga una imagen tradicional y encorsetada. Esta premisa se verifica gracias al contraste aportado por Ma French Bank. Se ha identificado que, aunque la RA es menos inmersiva que la RV, el que el smartphone y las RRSS sean sus principales valedores, la convierten en un actor de primer orden para la publicidad centrada en los centennials. Espacios como TikTok acogen, si se precisa, la cualidad de retransmitir el hecho promocional en streaming, lo que inculca a las acciones de marketing de propagabilidad in situ. En las RMe las interrelaciones 2.0 adquieren cualidades de intercambio social.

La publicidad 2.0 no se entiende, por definición, sin actos interpersonales. Si se pretende que un proyecto triunfe hay que buscar taxativamente dentro de esta vertiente de la comunicación. Los nuevos sistemas de socialización y retransmisión de contenidos, como TikTok o Twitch (Hilvert et al., 2018), favorecerán nuevos modos de hacer publicidad a través de la RA (Recktenwald, 2017). Por tanto, el sector juvenil se muestra más accesible a través de estas iniciativas, las cuales, gracias a su novedad, se perciben como más atractivas. Con el tiempo, la masa social de estos relatos, por lógica demográfica, irá incrementándose, dato a considerar por los agentes de marketing.

A la par, el que la publicidad expandida se integre como un elemento nativo de la RRSS da como resultado que la promoción sea consumida de forma transparente y desapercibida, superando la saturación publicitaria de otros medios. Desde el punto de vista del front end visual, adquirir iconografía de la cultura del videojuego, tales como el pixel art o tipografías monoespaciadas, supone que la adquisición del mensaje inserto en el advergame RA sea productiva para el anunciante.

Las RMe se caracterizan por la multimodalidad. Estas interacciones aportan mayor recuerdo en los sujetos que la experimentan (Gutiérrez y Tyner, 2012). La publicidad RA dispone de más y mejores canales sensoriales para la creación de piezas creativas. Imagen, audio y tacto confluyen para conformar una disruptiva forma de reconfigurar la discursividad digital 2.0. Esta cualidad, en simbiosis con las RRSS, la posicionan como un sistema de marketing sensorial de primer orden (Jiménez-Marín et al., 2019). En línea con esto, los creativos tienen modelos interactivos por descubrir. La RA permite implementar videojuegos (advergames) y aplicaciones en la propia RRSS, formas de interacción y modos de consumir contenidos inesperados.

La RA pone a disposición de quien lo requiera la percepción al detalle. Las pantallas con altísimas resoluciones, los nuevos sensores de los smartphones y las posibilidades de los softwares development kit (SDK) RA (ARCore, ARKit) permiten apreciar de forma rigurosa los detalles introducidos en los objetos virtuales. 3D, luces, sombras, texturas y demás, son asimilados más y de mejor manera. En parte, se debe a la sensación que tiene el usuario de ocupar un lugar subjetivo destacado dentro del entorno comercial virtualizado frente a sí. Conforme a lo dicho, la simulación fidedigna de la RA da al público objetivo la opción de probar el funcionamiento de productos de forma compleja. Ahora el usuario puede testear en remoto aquello que se le antoje como si tuviera el producto ante él y, si lo demanda la campaña, de forma gamificada. 
Vistos los resultados, la publicidad expandida en RRSS comienza a perfilar un estándar mediante una interacción y discurso específicos basados en el advertainment y la gamificación, la cual cobra su máxima dimensión y eficacia en la transmedialidad.

Tabla 2. Ventajas y consideraciones del advergame RA en RRSS similares a TikTok

\begin{tabular}{|l|l|}
\hline Ventajas & Consideraciones \\
\hline Transmedialidad & Cierta fragmentación entre RRSS \\
\hline Inmersión RMe & Latencia \\
\hline Multimodalidad & Experiencias duran poco \\
\hline Sociabilidad 2.0 & Escasa repetición del advergame RA \\
\hline Transparencia de la RA en RRSS & Falta de estándar de interacción \\
\hline Simulación & Desconocimiento entre público general \\
\hline Sistemas interactivos por descubrir & La RA tiene múltiples tecnologías \\
\hline Percepción al detalle & \\
\hline Novedad-engagement & \\
\hline Discurso propio & \\
\hline Interacción específica a la campaña & \\
\hline
\end{tabular}

Fuente. Elaboración propia

\section{Conclusiones}

En su conjunto el estudio ratifica los objetivos planteados. En primer lugar, parece acertado pensar que los advergames RA en RRSS encuentran en el transmedia un ecosistema óptimo para incrementar su eficacia, idea que parece cumplirse sin ambages. En esta línea, todo apunta a que la RA empleada en el campo de la publicidad cuenta con un discurso propio para la transmisión de mensajes promocionales de distinta índole, siendo un vehículo de calidad para las campañas con estrategias transmedia y/o de advertainment, incluidas aquellas que invocan al juego como reclamo.

El proyecto de investigación constata los beneficios de las técnicas inmersivas RA en el contexto de las campañas transmedia. También arroja la presencia de un discurso con el potencial de normalizar su uso en el seno del marketing cuando este tipo de sistemas TIC llegue a un número suficiente de la población, pues el hardware y el software han alcanzando un estado de madurez adecuado.

La publicidad expandida tendría propiedades pull, ya que el sujeto en la RA se convierte en el protagonista, y pasaría a adquirir todas las connotaciones y valores de marca al usar filtros inmersivos. Posiblemente, el mismo se sentirá uno con la institución emisora y compartirá con sus contactos y demás dicha idea. El anunciante también se retroalimentará de esta sinergia y, dada la edad de estos usuarios, entre otras cuestiones el emisor rejuvenecerá al convertirse en un elemento icónico para la generación $z$.

Como aportación, la publicidad expandida y el advergame en RRSS se hallan en un estadio de integración avanzado por lo que llegarán a ser unos canales más entre la generación z. Quedó patente que los integrantes de estos grupos lo perciben como algo normal, sin ni siquiera apreciar que están ante un entorno de RA, ya que lo evalúan como algo innato de las RRSS.

El estudio ha permitido identificar que los videojuegos publicitarios RA son recibidos muy positivamente. Esto implica que este relato alberga un componente de seducción en el subconsciente de los centennials por, entre otras razones, sentirse partícipe de algo especial. Dicha evidencia debería ser algo a considerar al plantear campañas transmedia cuya meta sea alcanzar este estrato social, cada vez más reticente a la mal llamada publicidad convencional. 


\section{Bibliografía}

Aguilera-Moyano, J. y Baños-González, M. (2016). Branded entertainment. Cuando el Branded Content se convierte en entretenimiento. ESIC.

Alberich-Pascual, J. y Gómez-Pérez, F. J. (2017). Tiento para una estética transmedia. Vectores estéticos en la creación, producción, uso y consumo de narrativas transmediales. Tropelías: Revista de Teoría de la Literatura y Literatura Comparada, (28), 9-20. https://doi.org/10.26754/ ojs tropelias/tropelias.2017282044.

American Marketing Association (2021). Marketing vs. Advertising. AMA. American Marketing Association. https://www.ama.org/pages/marketing-vs-advertising/\#: :text=In\%20basic\%20 terms $\% 2 \mathrm{C} \% 20$ marketing $\% 20 \mathrm{is}$, is $\% 20 \mathrm{a} \% 20$ component $\% 20 \mathrm{of} \% 20$ marketing.

Aparici-Marino, R. y García-Marín, D. G. (2018). Prosumidores y emirecs: Análisis de dos teorías enfrentadas. Comunicar: Revista científica iberoamericana de comunicación y educación, (55), 71-79. https://doi.org/10.3916/C55-2018-07.

Araque, J. (2021). TikTok lanza su primer efecto en Realidad Aumentada y es alucinante, pero solo está disponible para algunos móviles. Business Insider. https://www.businessinsider.es/tiktoklanza-efecto-realidad-aumentada-especial-iphone-786381.

Azkunaga-García, L., Gaztaka-Eguskiza, I. y Eguskiza-Sesumaga, L. (2019). Nuevas narrativas en televisión: La Realidad Aumentada en los telediarios de Antena 3. Revista de Comunicación, 18(2), 25-50. https://doi.org/10.26441/RC18.2-2019-A2.

Azuma, R. T. (1997). A survey of augmented reality. Presence: Teleoperators \& Virtual Environments, 6(4), 355-385. https://doi.org/10.1162/pres.1997.6.4.355.

Bajaña-Mendieta, I., Ronald-Cruz, F. R. M., Can-Sing, C. y Puris-Cáceres, A. (2018). Impacto de la publicidad usando realidad aumentada con aplicaciones en dispositivos Android. Universidad Ciencia y Tecnología, (1), 115-120. https://www.uctunexpo.autanabooks.com/index.php/uct/article/view/56/57.

Baños-González, M. y de Aguilera-Moyano, J. (2017). Las comunicaciones en el nuevo paradigma de marketing. Experiencias, relevancia, engagement y personalización. Presentación. Revista ICONO14 Revista científica de comunicación y tecnologías emergentes, 15(2), 1-15. https://doi.org/10.7195/ri14.v15i2.1098.

Bauman, Z. (2015). Modernidad líquida. Fondo de cultura económica.

Beldico-Pachot, H. (2021). WeStart, fruit d'un partenariat entre Ma French Bank X Publicis Sapient. Jai un pote dans la com. https://jai-un-pote-dans-la.com/westart-fruit-un-partenariatentre-ma-french-bank-publicis-sapient/.

Bernal, C. A. (2010). Metodología de la Investigación. Pearson Educación.

Cabero-Almenara, J. y Pérez-Díez De-los-Ríos, J. L. (2018). Validación del modelo TAM de adopción de la Realidad Aumentada mediante ecuaciones estructurales. Estudios sobre Educación, (34), 129-154. https://doi.org/10.15581/004.34.129-153.

Colussi, J. y Assunção-Reis, T. (2020). Periodismo inmersivo. Análisis de la narrativa en aplicaciones de realidad virtual. Revista Latina, (77), 19-32. https://doi.org/10.4185/RLCS-2020-1447.

De-Lara-González, A. y Arias-Robles, F. (2017). Mediamorfosis: Perspectivas sobre la innovación en periodismo. Universidad Miguel Hernández. 
Díaz-Valladares, G. y Peñola-Yañez, M. G. (2015). La teorización y las técnicas participativas del proceso dialéctico en la educación popular. Tendencias pedagógicas, (26), 253-262. https://doi. org/10.15366/tp2015.26.

Durán-Medina, J. F. (2014). Comunicación 2.0 y 3.0. Asociación y Científica Iberoamericana. ACCI.

Gamonal-Arroyo, R. (2012). Del boceto al diseño: la materialización del discurso visual en el diseño gráfico. Vivat Academia, (119), 42-57. https://doi.org/10.15178/va.2012.119.42-57.

Gartner (2018). 5 Trends Emerge in the Gartner Hype Cycle for Emerging Technologies, 2018. Gartner. https://www.gartner.com/smarterwithgartner/5-trends-emerge-in-gartner-hype-cycle-foremerging-technologies-2018.

Gómez-Nieto, B. (2017). Fundamentos de la publicidad. ESIC editorial.

Gómez-Nieto, B. y Tapia-Frade, A. (2017). La enseñanza de la Publicidad a través de la guía docente: el caso de la asignatura Teoría General de la Publicidad. Revista Complutense de Educación, 28(2), 391-407 https://doi.org/10.5209/rev_RCED.2017.v28.n2.49401.

Gutiérrez-Martín, A. y Tyner, K. (2012). Educación para los medios, alfabetización mediática y competencia digital. Comunicar: Revista cientifica iberoamericana de comunicación y educación, 19(38), 31-39. https://doi.org/10.3916/C38-2012-02-03.

Hawker, K. \& Carah, N. (2020). Snapchat's augmented reality brand culture: sponsored filters and lenses as digital piecework. Continuum, 34(6),1-18. https://doi.org/10.1080/10304312.2020.1827370.

Herrman, J. (2019). How TikTok is rewriting the world. The New York Times, 10. https://www. nytimes.com/2019/03/10/style/what-is-tik-tok.html.

Hidalgo-Marí, T. y Segarra-Saavedra, J. (2019). Publicidad de la publicidad. Las redes sociales como soportes de comunicación de las agencias de publicidad. adComunica: revista cientifica de estrategias, tendencias e innovación en comunicación, (18), 101-122. https://doi. org/10.6035/2174-0992.2019.18.7.

Hilvert-Bruce, Z., Neill, J. T., Sjöblom, M. \& Hamari, J. (2018). Social motivations of live-streaming viewer engagement on Twitch. Computers in Human Behavior, 84, 58-67. https://doi.org/10.1016/j. chb.2018.02.013.x.

Jenkins, H. (2010). Transmedia storytelling and entertainment: An annotated syllabus. Continuum, 24(6), 943-958. https://doi.org/10.1080/10304312.2010.510599.

Jenkins, H., Ford, S. \& Green, J. (2013). Spreadable Media. Creating Value and Meaning in a Networked Culture. NY Univ. Press.

Jenkins, H., Ford, S. y Green, J. (2015). Cultura transmedia: la creación de contenido y valor en una cultura en red (Vol. 60). Editorial Gedisa.

Jiménez-Marín, G., Bellido-Pérez, E. y Cortés, Á. L. (2019). Marketing sensorial: el concepto, sus técnicas y su aplicación en el punto de venta. Vivat Academia, (148), 121-147. http://doi.org/10.15178/ va.2019.148.121-147.

Jiménez, G. y Marinas, L. (2020). Archivo camp. Memorias visuales e identidades outsider. Arte y Politicas de Identidad, 22, 117-142. https://doi.org/10.6018/reapi.433961.

Kerr, G. \& Richards, J. (2020). Redefining advertising in research and practice. International Journal of Advertising, 1-24. https://oi.org/10.1080/02650487.2020.1769407. 
Kotler, P. y Armstrong, G. (2013). Fundamentos de Marketing. Pearson Prentice Halls. Madden, C. (2017). Hello Gen Z: Engaging the Generation of Post-Millennials. Hello Clarity. Maestro-Espínola, L., Cordón-Benito, D. y Abuín-Vences, N. (2019). Integración de los mensajes comerciales y el contenido editorial en la prensa digital: publicidad nativa. Pensar la Publicidad, 13, 209-226. https://dx.doi.org/10.5209/pepu.65027.

Martí-Parreño, J. (2011). Publicidad expandida mediante realidad aumentada. MK: Marketing+ ventas, (267), 30-37. http://pdfs.wke.es/4/5/8/5/pd0000064585.pdf.

Martín-Ramallal, P. (2020a). Las 7W del periodismo inmersivo. Una propuesta discursiva para la postmodernidad. Razón y palabra, 29(102), 183-213. https://doi.org/10.26807/rp.v24i109.1693.

Martín-Ramallal, P. (2020b). Realidad virtual y publicidad transmedia. Un estudio multidisciplinar del advergaming inmersivo [Tesis Doctoral]. Universidad de Cádiz, Facultad de Comunicación y Ciencias Sociales, Universidad de Cádiz (UCA), Cádiz, España.

Méndiz-Noguero, A. (2012). Advergaming. Concepto, tipología, estrategia y evolución histórica. Revista ICONO14 Revista cientificas de comunicación y tecnologías emergentes, 8(1), 37-58. https://doi.org/10.7195/ri14.v8i1.279.

Mut-Camacho, M. \& Miquel-Segarra, S. (2019). La narrativa transmedia aplicada a la comunicación corporativa. Revista de Comunicación, 18(2), 225-244. https://doi.org/10.26441/ RC18.2-2019-A11.

Omar, B. \& Dequan, W. (2020). Watch, Share or Create: The Influence of Personality Traits and User Motivation on TikTok Mobile Video Usage. iJIM, 14(4), 121-127. https://doi.org/10.3991/ ijim.v14i04.12429.

Perry, T. S. (2020). Look Out for Apple's AR Glasses: With head-up displays, cameras, inertial sensors, and lidar on board, Apple's augmented-reality glasses could redefine wearables. IEEE Spectrum, 58(1), 26-54. https://dx.doi.org/10.1109/MSPEC.2021.9311420.

Phua, J., \& Kim, J. J. (2018). Starring in your own Snapchat advertisement: Influence of self-brand congruity, self-referencing and perceived humor on brand attitude and purchase intention of advertised brands. Telematics and Informatics, 35(5), 1524-1533. https://doi.org/10.1016/j.tele.2018.03.020.

Poplar Studio (2021). AR and 3D experiences on demand. Poplar Studio. https://poplar.studio/.

Rebolledo-Bueno, S. (2019). "Social media", interacción y publicidad. Percepción de los formatos y contenidos en la Web 3.0. Pensar la Publicidad, 13, 191-207. https://dx.doi.org/10.5209/ pepu.65026.

Recktenwald, D. (2017). Toward a transcription and analysis of live streaming on Twitch. Journal of Pragmatics, 115, 68-81. https://doi.org/10.1016/j.pragma.2017.01.013.

Ryan, K. M. (2018). Vertical video: rupturing the aesthetic paradigm. Visual Communication, 17(2), 245-261. https://doi.org/10.1177/1470357217736660.

Sabate, F., Berbegal-Mirabent, J., Cañabate, A. \& Lebherz, P. R. (2014). Factors influencing popularity of branded content in Facebook fan pages. European management journal, 32(6), 1001-1011. https://doi.org/10.1016/j.emj.2014.05.001.

Sánchez-Mesa Martínez, D. (2019). Narrativas transmediales: La metamorfosis del relato en los nuevos medios digitales. Editorial Gedisa. 
Sartori, G. (2012). Homo videns: la sociedad teledirigida. Taurus.

Scolari, C. A. (2013). Narrativas transmedia. Cuando todos los medios cuentan. Deusto.

Seemiller, C., \& Grace, M. (2018). Generation Z: A century in the making. Routledge. https://doi. org/10.4324/9780429442476.

Sidorenko-Bautista, P., Calvo-Rubio, L. M. y Canero-de-Julián, J. I. (2018). Marketing y publicidad inmersiva: el formato $360^{\circ}$ y la realidad virtual en estrategias transmedia. Miguel Hernández Communication Journal, (9), 19-47. https://doi.org/10.21134/mhcj.v0i9.227.

Sidorenko-Bautista, P., Herranz-de-la-Casa, J. M. \& Cantero-de-Julián, J. I. (2020). Use of New Narratives for COVID-19 reporting: from $360^{\circ}$ videos to ephemeral TikTok videos in online media. Trípodos 1(47), 105-12. https://doi.org/10.51698/tripodos.2020.47p105-122.

Southgate, D. (2017). The emergence of Generation $\mathrm{Z}$ and its impact in advertising: Long-term implications for media planning and creative development. Journal of Advertising Research, 57(2), 227-235. https://doi.org/10.2501/JAR-2017-028.

Strauss, J. \& Frost, R. (2016). E-marketing. Pearson. https://doi.org/10.4324/9781315506531.

Tamara-Quiroz, N. (2020). TikTok. La aplicación favorita durante el aislamiento. Revista Argentina de Estudios de Juventud, (14), 1-9. https://doi.org/10.24215/18524907e044.

TikTok for bussines (2021). Don't make ads. Make TikToks. TikTok. https://www. tiktokforbusinesseurope.com/es/.

Viñals-Blanco, A. (2016). El Ocio Conectado, móvil, transmedia y multisoporte de los jóvenes en la Era Digital. Fonseca, Journal of Communication, 13(13), 99-113. https://doi.org/10.14201/fjc20161399113.

Vitelar, A. (2019). Like me: Generation $\mathrm{Z}$ and the use of social media for personal branding. Management Dynamics in the Knowledge Economy, 7(2), 257-268. https://doi.org/10.25019/ MDKE/7.2.07.

Yin, R. K. (2017). Case study research and applications: Design and methods. Sage publications.

Yoo, S., Ackad, C., Heywood, T. \& Kay, J. (2017). Evaluating the Actual and Perceived Exertion Provided by Virtual Reality Games. In Proceedings of the 2017 CHI Conference on Human Factors in Computing Systems (pp. 3050-3057). ACM, Denver, USA. https://doi. org/10.1145/3027063.3053203.

Zuo, H. \& Wang, T. (2019). Analysis of Tik Tok user behavior from the perspective of popular culture. Frontiers in Art Research, 1(3). 1-5. https://doi.org/10.25236/FAR.20190301. 